\title{
A Note on Translations and Transliterations
}

Unless otherwise noted, all translations are mine. Generally I phoneticize Tibetan names according to the Tibetan \& Himalayan Library's phonetics guidelines, with some exceptions. The variation in English phoneticization of some names reflects my effort to use the spelling preferred by living people to whom I refer. Those spellings are different from THL's system. All Tibetan names and terms are listed in the index using the Wylie system of transliteration. Where appropriate, I include the Wylie in parantheses within the text.

I refer to three monastic "catalogues" (dkar chag). To distinguish them, I use English-language titles that are based on elements of the Tibetan original. In the case of the Mirror of Memory Catalogue, I adapt the poetic title. For the Lamp of Teachings Catalogue I adapt the editor's pen name. This publication includes seventeenth- and eighteenth-century documents, one of which is the third catalogue. This I refer to descriptively as the Temple Wall Catalogue because it was displayed in calligraphy on the walls of the monastery. 
